\title{
Mortality in a feral population of muntjac Muntiacus reevesi in England
}

\author{
Arnold S. COOKE, Peter GREEN and Norma G. CHAPMAN
}

\begin{abstract}
Cooke A. S., Green P. and Chapman N. G. 1996. Mortality in a feral population of muntjac Muntiacus reevesi in England. Acta Theriologica 41: 277-286.

In Monks Wood National Nature Reserve in Cambridgeshire, England, the death occurred of approximately half of a large, feral population of muntjac deer Muntiacus reevesi (Ogilby, 1839) during January to April 1994. From their body mass and from post-mortem examination, the deer were evidently starving, and pneumonia was the ultimate cause of death in a number of cases. The incident coincided with increased foraging activity. Mortality was much reduced in 1995. Examination of a sample of deer shot in 1995 indicated body mass to be higher than for the 1994 casualties, but still lower than for deer from other sites. Without direct management of the population, future mortality incidents may be anticipated when the winter population is relatively high or weather conditions unfavourable.
\end{abstract}

English Nature, Northminster House, Peterborough PE1 1UA, UK (ASC); Fellowes Farm Equine Clinic, Abbots Ripton, Huntingdon, Cambs PE17 2LH, UK (PG); Larkmead, Barton Mills, Bury St Edmunds, Suffolk IP28 6AA, UK (NGC)

Key words: Muntiacus reevesi, mortality, starvation, post-mortem examination

\section{Introduction}

Escapes or liberations from scattered locations from 1901 until the present day have resulted in the widespread distribution of Chinese or Reeves' muntjac Muntiacus reevesi (Ogilby, 1839) within about half (745) of the $10 \mathrm{~km}$ grid squares in England and Wales (Chapman et al. 1994). As a long-lived, aseasonal breeder, with females able to conceive before one year of age and with the potential to produce a fawn at intervals of seven months (Chapman 1991), the species has the capability to establish dense populations under favourable conditions. The severe winter of 1962/1963 showed that periods of prolonged deep snow can be catastrophic. At that time there was little interest in the species and the information available is largely anecdotal. However, in some woodlands the losses were estimated at $70 \%$; in the absence of post-mortem examinations, deaths were attributed to cold, starvation or capture by dogs (Chapman et al. 1994). The die-off discussed in this paper presented an opportunity to establish the causes and extent of an unusually high level of winter mortality in an unmanaged population. 


\section{The study site and the deer population}

Monks Wood National Nature Reserve, located in Cambridgeshire, England extends to 157 ha and is dominated by oak Quercus spp. and ash Fraxinus excelsior. It is primarily surrounded by arable farmland, with some grassland and smaller areas of buildings, scrub and conifer plantation.

Muntjac were first reported in about 1970 . The population increased until the mid 1980s, since when it has remained at a high and fairly stable level (Cooke 1994). There is no culling in the reserve, although some deer are shot when they forage over adjacent farmland, especially in winter, and others are killed by vehicles on nearby roads.

\section{Methods}

Each spring since 1986, a total of 6-8 surveillance walks has been undertaken at dusk from January to May to monitor long-term changes in population level (Cooke 1994). In addition, the muntjac and the damage they caused to conservation interests were studied intensively from May 1993 to April 1994 (Cooke 1994). This latter work included fixed route walks of $8 \mathrm{~km}$ during which muntjac were counted in 82 plots of different habitat types inside and outside the wood; eight walks were completed each month, four at around midday and four finishing just after dusk. Plots were selected so that any deer inside them should have been visible, the purpose of the fixed route walks being to count deer in more readily observable situations. Therefore, numbers recorded depended both on deer density and on their behaviour.

Any deer found dead or dying on surveillance and fixed route walks were recorded. When it became apparent in the early months of 1994 that unusual numbers of dead deer were being found, the reserve staff and other regular visitors were asked to draw our attention to further casualties.

Deer that appeared freshly dead were usually removed from the wood. Carcases were weighed, sexed and examined in accordance with normal post-mortem protocol by a veterinary surgeon experienced in wildlife and ruminant pathology. In these cases, hair and hoof shedding had not occurred, and there should not be significant post-mortem weight change before this stage (Renloud and Smith 1978, Oates 1992). Where autolysis was not established, appropriate samples were taken for histology, microbiological culture and parasitological examination. Autolysed carcases were examined only by careful gross inspection. Rumen and bowel contents were recorded. Clean skulls were prepared by soft tissue removal and immersion in a hot solution of sodium perborate (Chapman and Chapman 1969). The age of young animals was assessed to the nearest week from the eruption and early wear of the teeth by reference to the skulls and mandibles of 20 known age, captive muntjac and 23 tagged, free-living muntjac of approximately known age from Suffolk (Chapman et al. 1985). Although some individual variation is to be expected, this was the most accurate method of age estimation available; agreement between captive and wild, tagged individuals of the same or similar ages was very close. Animals with a complete, fully erupted, permanent dentition with all cusps in wear were placed in a category of "two years and older" and are referred to as adults. Mandible length and zygomatic width were measured for the skulls of adult deer as indicators of body size.

For comparison with the casualties from 1994, 27 muntjac were shot from January to April 1995 as they emerged from the eastern and northern edges of Monks Wood to forage over arable fields. Also available for comparison were measurements for free-living deer, considered representative of muntjac in Britain, collected from eight counties in southern England January-April, 1977-1994 (some data already summarised by Chapman 1991). All of these areas experience similar climatic conditions.

An attempt was made to determine, from numbers of deer recorded on the fixed route walks, the extent of the decline in the early months of 1994. A second method was also used. During June and July 1993 a straight route of $1 \mathrm{~km}, 75 \mathrm{~m}$ inside the wood from its southern edge, was walked on five 
occasions. Each deer seen within $25 \mathrm{~m}$ of the route was recorded as being inside one of five 1 ha ( $200 \times$ $50 \mathrm{~m}$ ) plots. Density could then be given as mean number of deer per ha for the five replicate plots. The walk was repeated ten times in March and April 1994 for comparison with the previous summer.

Two sections of road close to the wood, of a total length of about $1.7 \mathrm{~km}$, were checked on foot for casualties at the end of March and April 1994 and March 1995. Meterological data were recorded by the Institute of Terrestrial Ecology at the research station immediately adjacent to the wood.

\section{Results}

\section{Observations on the dead deer}

From January to April 1994, 44 dead and two dying muntjac were seen by the authors in or adjacent to Monks Wood (Table 1). Of these deer, ten appeared to be road casualties. The casualties also included two still-born fawns. The main mortality was during February and March. No casualties were found after April.

Table 1. Number of muntjac casualties found in January-April 1994. Numbers in brackets are those subjected to full post-mortem investigation. * - including 10 road casualties, \# - no road casualties were found in April.

\begin{tabular}{|c|c|c|}
\hline \multirow{2}{*}{ Month } & \multicolumn{2}{|c|}{ Number of muntjac found dead or dying } \\
\hline & Dying or freshly dead ( $<1$ week) & Long dead (> 1 week) \\
\hline January & $1 \quad(1)$ & 0 \\
\hline February & $13(13)$ & 0 \\
\hline March & $8(7)$ & $15^{*}(3)$ \\
\hline April & $2 \quad(0)$ & $7 \#(0)$ \\
\hline Total & 24 & 22 \\
\hline
\end{tabular}

Twenty four of the freshest carcases found away from roads were subject to post-mortem investigation.

The first individual was found alive but terminally incapacitated in January. It was in relatively good body condition, but post-mortem examination and laboratory investigation revealed the presence of widespread abscessation of the mesenteric lymph nodes. Acid fast organisms were abundant on initial smears of the purulent material, but failed to culture. A presumptive diagnosis of avian tuberculosis was made.

The remaining 23 carcases, which were collected in February and March, were all found to be in poor condition with no evidence of perirenal or mesenteric fat deposits. Although secondary or minor pathological lesions were discovered, none of these was considered to be a significant contributing factor to the condition of the deer. Pneumonia, secondary to recumbency, appeared to be the final fatal insult upon several of the debilitated animals. Escherichia coli, Streptococcus sp. and Aeromonas sp. were recovered from pneumonic lung lobes. No evidence of 
tuberculosis was discovered in any carcase other than the first. Other histological findings included agonal congestion and oedema of lung tissue and post-mortem excavation of dermal tissues, perhaps by small mammals, particularly around the coronary bands of the hooves. There was no evidence of internal or external parasitism in any of the carcases examined. Yersinia enterocolitica was recovered from the bowel of one individual, but there was no evidence in the carcase of extra lumenal infection or active enteritis. With the exception of the first case in January, rumenal and bowel contents were sparse in all the carcases examined. There was no evidence of substantial or nutritious ingesta; small boluses of brown, dried leaves of various species, together with dried grasses, were present in most of the rumens. Large and small intestines contained small quantities of soft material and a few faecal pellets were present in the rectums. It was concluded that all but the first deer from January had collapsed or died due to starvation.

Of the 1994 casualties examined fully $(n=24), 11(46 \%)$ were first year deer, 5 $(21 \%)$ were second year deer while $8(33 \%)$ were adults. This contrasted with the 1995 shot sample $(n=27)$ for which the respective figures were $8(30 \%), 1(4 \%)$ and $18(67 \%)$. There were relatively more sub adults in the 1994 sample and more adults in the 1995 sample $\left(\chi^{2}=5.56, p<0.05\right)$. All of the first year deer examined in both samples were in the age range 20-40 weeks (the two fawns were not included in the sample of 24 fully examined in 1994); this age group appeared particularly vulnerable during the 1994 incident. Because of the relatively large number of deer in this age range in the 1994 sample, we have concentrated on analysing body mass data for this age class, as well as for adults (Table 2). Mean body mass for the four age/sex sub groups from the 1994 incident was 30 to $45 \%$

Table 2. Mean body mass (in $\mathrm{kg}$ ) of muntjac from the Monks Wood mortality incident of 1994, from the shot sample of 1995, and from elsewhere in Britain. The British data relate to animals that died during January to April inclusive. Masses significantly different by $t$-test from the mean of the British sample: ${ }^{*}-p<0.05,{ }^{* * *}-p<0.001$.

\begin{tabular}{|c|c|c|c|c|c|c|c|}
\hline \multirow{3}{*}{$\begin{array}{l}\text { Origin } \\
\text { Monks Wood } 1994\end{array}$} & \multirow{3}{*}{$\begin{array}{c}\text { Age } \\
\begin{array}{l}20-40 \\
\text { weeks }\end{array}\end{array}$} & \multicolumn{3}{|c|}{ Males } & \multicolumn{3}{|c|}{ Females } \\
\hline & & \multirow{2}{*}{$\begin{array}{l}n \\
5\end{array}$} & \multicolumn{2}{|c|}{$\begin{array}{c}\text { Mean body mass } \pm \text { SE } \\
\text { (\% of British mean })\end{array}$} & \multirow{2}{*}{$\begin{array}{l}n \\
6\end{array}$} & \multicolumn{2}{|c|}{$\begin{array}{c}\text { Mean body mass } \pm \text { SE } \\
(\% \text { of British mean })\end{array}$} \\
\hline & & & $5.6 \pm 0.7^{* * *}$ & $(60)$ & & $4.9 \pm 0.2^{* * *}$ & $(55)$ \\
\hline Monks Wood 1995 & $\begin{array}{l}20-40 \\
\text { weeks }\end{array}$ & 3 & $7.0 \pm 0.4^{*}$ & (75) & 5 & $7.6 \pm 0.5$ & $(85)$ \\
\hline Britain & $\begin{array}{l}20-40 \\
\text { weeks }\end{array}$ & 15 & $9.3 \pm 0.3$ & & 10 & $8.9 \pm 0.4$ & \\
\hline Monks Wood 1994 & Adult & 4 & $10.1 \pm 0.7^{* * *}$ & (70) & 4 & $7.7 \pm 1.1^{* * *}$ & $(60)$ \\
\hline Monks Wood 1995 & Adult & 8 & $13.0 \pm 0.6^{*}$ & $(90)$ & 10 & $12.0 \pm 0.4$ & (94) \\
\hline Britain & Adult & 60 & $14.4 \pm 0.2$ & & 30 & $12.8 \pm 0.2$ & \\
\hline
\end{tabular}


Table 3. Mean skull size (in $\mathrm{mm}$ ) for adult muntjac from the Monks Wood mortality incident of 1994, from the shot sample of 1995 and from elsewhere in Britain. Significantly different by $t$-test from the mean of the British sample: ${ }^{*}-p<0.05$.

\begin{tabular}{lrcrrr}
\hline \multirow{2}{*}{ Origin } & \multicolumn{2}{c}{ Males } & & \multicolumn{2}{c}{ Females } \\
\cline { 2 - 3 } \cline { 5 - 6 } & $n$ & Mean \pm SE & & $n$ & Mean \pm SE \\
\hline Monks Wood 1994 & 4 & $130.3 \pm 0.5$ & & 4 & $121.9 \pm 2.1^{*}$ \\
Monks Wood 1995 & 8 & $130.1 \pm 1.3$ & & 10 & $128.5 \pm 0.6$ \\
Britain & 23 & $129.0 \pm 0.8$ & & 16 & $126.7 \pm 0.9$ \\
& & Zygomatic width & & \\
Monks Wood 1994 & 4 & $77.8 \pm 0.8$ & & 4 & \\
Monks Wood 1995 & 8 & $77.7 \pm 1.0$ & & 10 & $72.9 \pm 1.4$ \\
Britain & 21 & $78.2 \pm 0.5$ & & 18 & $74.1 \pm 0.4$ \\
\hline
\end{tabular}

less than mean body mass for deer from elsewhere in Britain (Table 2); all of the differences between means were highly significant $(p<0.001)$. Comparing mean body masses for deer shot in 1995 with those from elsewhere in Britain, significant differences remained for young males $(p<0.05)$ and adult males $(p<0.05)$. Significant differences occurred between the 1994 and 1995 samples for adult males $(p<0.05)$, young females $(p<0.01)$ and adult females $(p<0.001)$. There were no differences between the mean ages for the $20-40$ week old sub groups, so lower body mass in the Monks Wood samples could not be attributed to the deer being slightly, but significantly, younger. None of the deer shot in 1995 was considered to be in poor or emaciated condition. Some renal and perinephric fat was present in all individuals, and some had significant intrapelvic fat deposits.

Skull measurements for adults are shown in Table 3 . The only significant differences between means were for mandible length of the 1994 females compared with the British sample $(p<0.05)$ and the 1995 sample from Monks Wood $(p<0.001)$.

\section{Field observations}

On surveillance walks from 1986 to 1993 , three dead deer were encountered in a total observation time of 69.0 hours (an average of 0.4 per 10 hours). During surveillance and fixed route walks in spring 1994, 15 dead deer were found in 85.5 hours ( 1.8 per 10 hours), a significant increase $\left(\chi^{2}=5.71, p<0.05\right)$. The remaining 31 casualties (Table 1 ) were found on other occasions.

During surveillance walks in 1995, one deer was found in 13.4 hours $(0.7$ per 10 hours). No road casualties were found during a search at the end of March 1995. Seven casualties, none of them fresh, were found on other occasions, but mortality on the scale of 1994 did not occur. 
Mean number of sightings per hour on the surveillance walks for the eight years 1986-1993 ranged from 14.1 to 22.5 . The mean \pm SE for the six walks, January-May 1994 was $21.5 \pm 4.1$ despite four of the walks taking place after the population decline in February. The population was therefore comparatively high prior to the decline. The mean \pm SE for the surveillance walks, January-May 1995 (one year after the mortality incident), was $15.2 \pm 1.3$, the second lowest mean for the ten years, 1986-1995.

As noted under Methods, numbers of deer recorded on fixed route walks depended on deer density and behaviour. The mortality incident was associated with a change in behaviour of the deer with the total number of sightings in fixed walk plots and the percentage of sightings outside the Reserve increasing up till February 1994 for both midday and dusk walks (Table 4). For the day and dusk visits, on a monthly basis from November 1993 to February 1994, there was a significant positive relationship between total sightings recorded and the percentage outside $\left(r_{\mathrm{S}}=0.93, p<0.01\right)$. Therefore, when using the data in Table 4 to estimate the extent of the decline it is important to compare time periods that have similar levels of activity outside the Reserve. Thus comparing numbers seen in January and February combined with those in March and April would over-estimate the decline because there was more foraging outside the Reserve in January and February. However, this criterion is reasonably well fulfilled by comparing January with March and April combined.

Table 4. Mean number of live muntjac recorded in 82 plots on fixed route walks, November 1993 - April 1994. Changes reflect alterations in deer foraging behaviour and density.

\begin{tabular}{|c|c|c|c|c|}
\hline \multirow{2}{*}{ Month } & \multicolumn{3}{|c|}{ Mean \pm SE number of deer counted } & \multirow{2}{*}{$\%$ outside } \\
\hline & In Reserve & Outside & Total & \\
\hline \multicolumn{5}{|c|}{ Midday ( $n=4$ fixed route walks) } \\
\hline November & $9.0 \pm 1.6$ & $0.3 \pm 0.3$ & $9.3 \pm 1.8$ & 3 \\
\hline December & $12.8 \pm 3.1$ & $0.3 \pm 0.3$ & $13.0 \pm 3.2$ & 2 \\
\hline January & $15.5 \pm 3.3$ & $2.0 \pm 1.2$ & $17.5 \pm 3.4$ & 11 \\
\hline February & $20.8 \pm 2.1$ & $9.8 \pm 3.1$ & $30.5 \pm 2.3$ & 32 \\
\hline March & $9.0 \pm 1.6$ & $1.5 \pm 0.6$ & $10.5 \pm 2.1$ & 14 \\
\hline April & $5.3 \pm 1.7$ & 0.0 & $5.3 \pm 1.7$ & 0 \\
\hline \multicolumn{5}{|c|}{ Dusk ( $n=4$ fixed route walks) } \\
\hline November & $9.8 \pm 2.4$ & $0.5 \pm 0.3$ & $10.3 \pm 2.3$ & 5 \\
\hline December & $13.3 \pm 1.5$ & $1.0 \pm 0.6$ & $14.3 \pm 1.7$ & 7 \\
\hline January & $21.3 \pm 4.1$ & $8.5 \pm 2.8$ & $29.8 \pm 5.8$ & 29 \\
\hline February & $22.3 \pm 1.8$ & $13.3 \pm 2.5$ & $35.5 \pm 2.2$ & 37 \\
\hline March & $15.0 \pm 1.6$ & $8.0 \pm 2.6$ & $23.0 \pm 3.3$ & 35 \\
\hline April & $11.8 \pm 2.5$ & $1.3 \pm 0.9$ & $13.0 \pm 3.2$ & 10 \\
\hline
\end{tabular}


The mean for day walks in March and April was $7.9(\mathrm{SE}=1.6,10 \%$ outside the Reserve) which was $55 \%$ less than the mean for January ( 17.5 with $11 \%$ outside (Table 4), $\mathrm{t}_{10}=2.99, p<0.05$ ). The mean for the dusk walks in March and April was 18.0 ( $\mathrm{SE}=2.8,26 \%$ outside the Reserve), $40 \%$ below the January mean (29.8 with $29 \%$ outside (Table 4 ), $\mathrm{t}_{10}=2.08,0.05<p<0.1$ ). Results for the straight walk through the wood showed a mean number of deer \pm SE per hectare of 1.20 \pm 0.13 in June and July 1993, and $0.66 \pm 0.24$ in March and April 1994. This indicated a decline of $45 \%$ although the means were not quite significantly different ( $\left.\mathrm{t}_{8}=2.01,0.05<p<0.1\right)$.

Rainfall and temperature in 1994 and 1995 were compared with mean data for the previous 30 years. In 1994, January was rather mild (mean temperature $1.7^{\circ} \mathrm{C}$ $>$ mean for 1964-1993) and wet (rainfall $+59 \%$ ), February and April were fairly typical and March was mild $\left(+2.3^{\circ} \mathrm{C}\right)$. Snow cover was restricted to two days in January and five in February. January to April 1994 was not therefore a period of unusually severe weather. January and February 1995 were mild $\left(+1.1^{\circ} \mathrm{C}\right.$ and $2.9^{\circ} \mathrm{C}$ respectively) and wet $(+107 \%$ and $+75 \%$ respectively), March was typical and April was mild $\left(+1.6^{\circ} \mathrm{C}\right)$ and dry $(-74 \%)$; there were just three days of snow cover in March.

\section{Discussion}

The fixed route walk focused on readily observable parts of the wood and the surrounding fields. For most of the year, deer activity tends to be concentrated inside the woodland blocks (unpublished observations). But during early 1994, sightings on the fixed route walks increased, indicating deer were foraging more widely. At the same time an unusually large number of deer were killed on adjacent roads. This increased foraging coincided with the peak of mortality in February and March 1994.

The three estimations of the extent of the decline ranged from $40 \%$ to $55 \%$ with a mean of $47 \%$. This mortality incident was not anticipated and so, when it occurred, field techniques being used for other purposes were adapted to provide an indication of the extent of the population decline. However, the estimates are reasonably consistent and suggest a loss of (almost) half of the population. The density recorded on the straight walk in the summer of 1993, 1.2 deer/ha, may provide an indication of the overall density in the wood before the mortality. Extrapolating this figure to the wood as a whole suggests a total population of up to 190 , with up to 90 dying in early 1994 . About half this number were found dead or dying. That such a proportion of casualties might be found was probably due both to efforts made to locate them and to the fact that many dying animals seemed to lie on the piles of hay left after cutting operations on the rides and fields. It is also true that some of the casualties found just outside the wood may have originated from neighbouring populations rather than from the Reserve. 
The terminal pneumonia which affected a number of the deer indicated an ante-mortem period of recumbency. The weakness and inanition which gave rise to the recumbency appeared to have been the result of starvation. The decrease in mean body mass for the four age/sex sub groups in Table 2 varied from $30 \%$ to $45 \%$, and it is pertinent to examine why the deer were starving. Weather was typical for the time of year. Evidence from the surveillance walks indicated that the population level was high prior to the incident. This will have led to increased competition for food. In the long term, because of a high density of deer, there has been impoverishment in the wood of food sources such as bramble Rubus fruticosus and dogs mercury Mercurialis perennis (Cooke et al. 1995). Seasonally, February is the most difficult month of the year for the deer as it is cold, and browsing and grazing have depleted the previous years growth; new growth, eg leaves of bluebell Hyacinthoides non-scripta and honeysuckle Lonicera periclymenum, is only just starting to become available. Rumen contents in the 1994 casualties were restricted to dead leaves and dried grasses. Rumen analyses in the early months of the year from elsewhere have demonstrated the importance of green forage such as bramble, ivy Hedera helix and ferns (Jackson et al. 1977, Harris and Forde 1986).

The most vulnerable group in the 1994 mortality incident were those aged $20-40$ weeks. It is noticeable that in the shot sample of 27 in 1995, only one was in its second year. The mortality had seemingly killed virtually all of the young born in 1993. High rates of mortality in young deer during their first winter have been identified in populations of red deer Cervus elaphus in Scotland and in related species in New Zealand, leading to the recognition of a Winter Death Syndrome (Haigh and Hudson 1993, Ross 1994). Affected animals become emaciated, debilitated and comatose, eventually succumbing to a variety of secondary diseases. The underlying factor appears to be starvation, although severe parasitism and particularly inclement weather are also implicated. In contrast to the reports of Winter Death Syndrome in red deer, the deaths in the muntjac reported here were not associated with internal or external parasites and there was no influence of atypically adverse weather. Post-mortem examination of Winter Death Syndrome victims usually reveals impaction of the colon and rectum with large quantities of hard dry material; this was not a feature of the muntjac carcases. The particular susceptibility of first year muntjac in Monks Wood is similar to the findings in Winter Death Syndrome of red deer, in which late born calves account for most deaths. This may be due to a combination of factors including the high metabolic rate of young deer compared to young cattle or sheep. Their lower critical temperature lies at a higher level than cattle or sheep, they have poor insulation from their coats and they carry fewer energy reserves (Ross 1994). When food is scarce and competition intense, younger deer are also less likely to succeed in finding an adequate daily intake. Recently reported studies on roe deer Capreolus capreolus have revealed lower survival for juveniles than for adults in a population showing density-dependent effects on body weight and reproduction (Gaillard et 
al. 1993) and a reduction in juvenile body weight, in particular, as the density of another population increased following the cessation of hunting (Vincent et al. 1995).

Skull measurements indicated that adult muntjac are not smaller in Monks Wood than elsewhere, although smaller females may have died in 1994. Mean body masses of the age/sex sub groups in the shot sample in 1995 were 6 to $25 \%$ below the mean for deer from elsewhere in Britain. So even though the population was at a relatively low level in 1995 and no significant mortality incident occurred, body condition was sub optimal. As food resources are clearly limiting, further incidents are to be anticipated, especially when the winter population is high and weather is severe. Hot, dry summers that inhibit normal growth of food plants may also increase mortality in the following winter.

Although the level of mortality in 1994 was unprecedented to date at the site, incidents have been noted in the past eg in 1991 (D. Massen and J. Croft, pers. comm.). Population control is being considered as part of an integrated programme to manage the deer and the habitat in order to safeguard conservation interests in the wood. Such control may also help to avoid losses through starvation as occurred in 1994.

Acknowledgements: We thank the staff of English Nature and the Institute of Terrestrial Ecology for helping us find carcases in 1994. The field work during 1993/4 was undertaken while A.S.C. was on secondment to I.T.E. Mr A. Frost of I.T.E. supplied the meteorological data. Mr S. Sanderson and Ms E. Major prepared and measured the skulls, and staff of the Veterinary Investigation Service of the Ministry of Agriculture, Fisheries and Food contributed to the post-mortem examinations. We also thank Mr A. Rowell and Mr S. Raby for allowing the culling of deer on their land in 1995. We are grateful to the many people who supplied N.G.C. with the specimens used in the comparative analysis. Finally, we thank Dr A. Mitchell-Jones and Mr I. Smith for commenting on an earlier draft of the manuscript.

\section{References}

Chapman D. I. and Chapman N. G. 1969. The use of sodium perborate $\left(\mathrm{NaBO}_{3}-4 \mathrm{H}_{2} \mathrm{O}\right)$ in the preparation of mammalian skeletons. Journal of Zoology, London 159: 522-523.

Chapman D. I., Chapman N. G. and Coles C. M. 1985. Tooth eruption in Reeves muntjac (Muntiacus reevesi) and its use as a method of age estimation (Mammalia: Cervidae). Journal of Zoology, London 205: 205-221.

Chapman N. G. 1991. Chinese muntjac Muntiacus reevesi. [In: The handbook of British mammals. 3rd edition. G. B. Corbet and S. Harris, eds]. Blackwell, Oxford: 526-532.

Chapman N., Harris S. and Stanford A. 1994. Reeves muntjac Muntiacus reevesi in Britain: their history, spread, habitat selection, and the role of human intervention in accelerating their dispersal. Mammal Review 24: 113-160.

Cooke A. S. 1994. Colonisation by muntjac deer Muntiacus reevesi and their impact on vegetation. [In: Monks Wood National Nature Reserve. The experience of 40 years 1953-1993. M. E. Massey and R. C. Welch, eds]. English Nature, Peterborough: 45-61.

Cooke A. S., Farrell L., Kirby K. J. and Thomas R. C. 1995. Changes in abundance and size of dogs mercury apparently associated with grazing by muntjac. Deer 9: 429-433. 
Gaillard J.-M., Delorme D., Boutin J.-M., Laere G. van, Boisaubert B. and Pradel R. 1993. Roe deer survival patterns: a comparative analysis of contrasting patterns. Journal of Animal Ecology 62: $778-791$.

Haigh J. C. and Hudson R. J. 1993. Farming wapiti and red deer. Mosby, St Louis: 1-369.

Harris S. and Forde P. 1986. The annual diet of muntjac (Muntiacus reevesi) in the Kings Forest, Suffolk. British Ecological Society Bulletin 17: 19-22.

Jackson J. E., Chapman D. I. and Dansie O. 1977. A note on the food of muntjac deer (Muntiacus reevesi). Journal of Zoology, London 183: 546-548.

Oates D. 1992. Time of death. [In: Wildlife and forensic field manual. D. Oates, ed]. Colorado Division of Wildlife, Fort Collins: 82-111.

Renloud E. and Smith H. 1978. Glaisters medical jurisprudence and toxicology. Churchill, Livingstone: $1-771$.

Ross H. M. 1994. Winter death syndrome. [In: Management and diseases of deer. T. L. Alexander and D. Buxton, eds]. Veterinary Deer Society, London: 130-132.

Vincent J. P., Bideau E., Hewison A. J. M. and Angibault J. M. 1995. The influence of increasing density on body weight, kid production, home range and winter grouping in roe deer (Capreolus capreolus). Journal of Zoology, London 236: 371-382.

Received 25 November 1995, accepted 1 June 1996. 